\title{
EL VALOR DE LA EXPERIENCIA DEL ALUMNO COMO CONTENIDO EDUCATIVO
}

\author{
The value of the student's experience as educational \\ content
}

Pedro ORTEGA RUÍZ y Eduardo ROMERO SÁNCHEZ

Universidad de Murcia. España.

portega@um.es; eromero@um.es

https://orcid.org/0000-0002-3882-0544; https://orcid.org/0000-0001-5090-0961

Fecha de recepción:08/07/2020

Fecha de aceptación: 07/08/2020

Fecha de publicación en línea: 01/11/2020

Cómo citar este artículo: Ortega Ruíz, P. y Romero Sánchez, E. (2021). El valor de la experiencia del alumno como contenido educativo. Teoría de la Educación. Revista Interuniversitaria, 33(1), 89-110. https://doi.org/10.14201/teri.23615

RESUMEN

Este artículo reflexiona sobre la importancia de la experiencia del alumno en su proceso educativo, y se inspira en la antropología y la ética de Levinas. Parte del concepto del ser humano como ser histórico, vulnerable, situado en una circunstancia, y de la ética como una respuesta compasiva al otro en su situación de vulnerabilidad y necesidad. La pedagogía cognitiva, al prescindir de la experiencia, se ha visto obligada a utilizar el juicio moral como estrategia adecuada (y única) para promover y facilitar la conducta moral, según la ética kantiana. Una concepción del hombre sesgada, mutilada no puede dar cuenta de cómo responde a la demanda del otro en su situación concreta. La educación se concibe como acompañamiento, acogida y respuesta compasiva al otro, como un nuevo nacimiento y el comienzo de algo nuevo. Se propone "otro modo» de educar que tenga a la experiencia como núcleo de la acción educativa. Este modelo de educación se traduce en: a) abandono de la filosofía idealista; b) compromiso político y social; c) presencia de la experiencia en el 
proceso educativo; d) presencia de la ética compasiva como su eje vertebrador; e) un nuevo discurso y un nuevo lenguaje; f) el testimonio del profesor como referente de la experiencia de los valores éticos; y g) la narración como instrumento privilegiado para la acción educativa. Se reivindica otra fuente de pensamiento que dé cuenta del ser humano en su totalidad: ser dotado de razón y también de sentimientos, superando, de este modo, la concepción dualista de la filosofía cartesiana.

Palabras clave: Levinas; educación; ética; alteridad; compasión; experiencia; narración.

\section{ABSTRACT}

This paper reflects on the importance of the student's experience in their educational process and is inspired by the anthropology and ethics of Emanuel Levinas. It starts from the concept of the human being as a historical, vulnerable being, situated in a circumstance, and of ethics as a comparative response to the other in their situation of vulnerability and need. Cognitive pedagogy, having dispensed with experience, has been forced to use moral judgment as an adequate (and unique) strategy to promote and facilitate moral conduct, according to Kantian ethics. A biased, mutilated conception of man cannot account for how he responds to the demand of the other in his concrete situation. Education is conceived as accompaniment, welcome and comparative response to the other, as a new birth and the beginning of something new. It is proposed "another way» of educating that has experience as the nucleus of educational action. This model of education translates into: a) abandonment of idealistic philosophy; b) political and social commitment; c) presence of experience in the educational process; d) presence of compassionate ethics as its backbone; e) a new discourse and a new language; f) the teacher's testimony as a reference to the experience of ethical values; and g) narration as a privileged instrument for educational action. Another source of thought is claimed that tells of the human being in its entirety: being endowed with reason and with feelings, thus overcoming the dualistic conception of cartesian philosophy.

Key words: Levinas; education; ethics; alterity; compassion; experience; narration.

\section{INTRODUCCIÓN}

Durante décadas la sociedad viene demandando a la escuela la solución de los problemas sociales que ella misma había creado: violencia, drogadicción, contaminación ambiental... Se instauró, así, una corriente de pensamiento que propugnaba la mejora de la eficacia del sistema educativo, y encontró en la denominada racionalidad tecnológica su soporte teórico y práctico para su implantación. La educación debería estar volcada a satisfacer las necesidades del sistema socio-económico como un elemento más del engranaje social. Las apelaciones a la educación integral del alumno quedaban reducidas a simples declaraciones formales sin trascendencia práctica en la formación de los alumnos. Sin embargo, la finalidad principal de la 
educación no es conseguir un trabajo, ni habilitar para funcionar en el mercado, sino transformar una existencia. "Plantear la educación desde la estrechez de la lógica económica es ofrecer una moneda falsa, pues el acto educativo tiene que ver con el don». (Bárcena, 2018, p. 75).

Después de décadas intentando reformar el sistema educativo mediante la aplicación de leyes distintas, y visto el escaso éxito de las mismas, al menos en España, deberíamos aprender que el éxito de los cambios en el sistema educativo no está vinculado, necesariamente, a una normativa promulgada a tal efecto, sobre todo si se prescinde de la formación adecuada de los profesores que la han de implementar. La historia lo viene confirmando. El cambio o mejora de la educación no responde, necesariamente, a la implementación de determinadas normas o leyes que den lugar «a un actuar tecnocrático o a un hacer pragmático. Reformar está gobernado por valores, y delimita un intento de remodelación de unas y otras circunstancias sociales a la luz de esos valores». (Zufiaure y Hamilton, 2015, p. 197). Estamos de acuerdo en que

los sistemas educativos precisan ser estructurados en función de las transformaciones acaecidas en estas sociedades. Las reivindicaciones praxiológicas de la práctica educativa necesitan cambios en el tiempo, pues son los contextos los que determinan las necesidades que deben ser ejecutadas mediante las acciones educativas. (Pallarés, Chiva, Planella y López, 2019, p. 125),

pues el sistema educativo no es ajeno al conjunto social del que forma parte. Pero siempre se ha de salvaguardar la primacía del ser humano, pues el orden social está para hacer posible la realización humana de cada individuo. Lo contrario significaría la defensa de una estatalitación de la educación y el sometimiento del individuo a la voluntad del poder establecido.

La reforma del sistema educativo debe ir acompañada de un cambio en nuestro modo de pensar y entender al hombre en su relación con el mundo y con los demás. Ello conlleva: a) la vuelta a la consideración ética del ser humano como ser relacional; b) el abandono de la filosofía idealista que sigue impregnando el discurso pedagógico y la praxis educativa; c) atención y cuidado al alumno, a sus necesidades y aspiraciones, no tanto a las exigencias del programa curricular; d) actitud ética hacia el alumno; que el educador se pregunte por el otro, de su relación ética con él de quien debe responder; e) formación adecuada del profesorado para promover la educación ético-moral del alumno, no solo el aprendizaje de conocimientos y competencias; y f) incorporar al educando como sujeto histórico del proceso educativo.

Por ello demandamos la recuperación del sujeto en el proceso educativo, de modo que este ocupe el lugar central que le corresponde, y sea él el punto de partida y de llegada de la acción educativa. No hay educación sin una relación ética entre educador y alumno. Podrá haber transmisión de saberes y competencias (instrucción), pero no educación. 
En toda acción educativa hay siempre una pregunta: ¿quién es el alumno para el educador?, ¿cuál es su relación con él? Sin formularse esta pregunta ética no puede iniciarse el proceso educativo, porque sin la creación de un espacio ético en la relación educativa, no hay educación. (Ortega y Romero, 2014, p. 87; cursiva del original).

Entendemos la acción educativa como respuesta de acogida a alguien que vive en una situación concreta. Esta "circunstancia» condiciona todo el proceso educativo, pues nunca se educa en el vacío. Es la experiencia del educando, en su singularidad, la que debe marcar el contenido y el ritmo del proceso educativo. Es a un individuo concreto, a alguien a quien se pretende educar en la experiencia de una vida también concreta. La educación acontece siempre en el tiempo y en el espacio, en un contexto marcado por la relación ética que se mantiene con los demás y con el mundo. Asumir la experiencia del alumno como elemento constitutivo de la educación condiciona el discurso y el lenguaje pedagógico; exige otro modo de entender al ser humano como ser histórico y otro modo de relacionarse con él. Exige, por tanto, otro modo de educar. La experiencia del alumno es la «circunstancia» indispensable para educar, constituye el contenido de la acción educativa para evitar una "educación» a seres imaginarios. Nos alejamos, por tanto, de una praxis educativa que ha considerado al alumno como objeto o tema de conocimiento en aras de unos supuestos resultados académicos, olvidando, así, el carácter singular e irrepetible de todo ser humano que solo se entiende desde la singularidad y la excepcionalidad. "Si entendiéramos la educación como un proceso controlado y controlable, evaluable, el sujeto de la educación nunca aparecería como una persona diferente e incomparable». (Bárcena y Mèlich, 2000, p. 77).

Aunque Levinas no ha hecho de la educación una cuestión u objeto de estudio, su obra, sin embargo, constituye una fuente fecunda para la investigación pedagógica y la praxis educativa. De un lado, su concepción del hombre como ser histórico, vulnerable, condicionado por su circunstancia; y de otro, su interpretación del ser humano como ser para el otro, llamado a la existencia humana solo en la medida en que se hace responsable del otro, constituyen la base teórica para una educación con rostro humano. Una educación que hace de la "circunstancia" condición necesaria para educar, y de la compasión hacia el otro, el paso obligado para la constitución del ser humano en sujeto ético.

Todo discurso pedagógico y toda praxis educativa son deudores de una determinada antropología y de una ética. Este trabajo se reconoce deudor de la antropología y ética levinasianas. Considera al educando el centro del proceso educativo y como ser vulnerable y necesitado de acogida y ayuda, pues todo ser humano es «extranjero, huérfano y viuda» en la expresión simbólica y bíblica de Levinas.

\section{LeVinas, PUnto de Partida}

La filosofía idealista ha impregnado el discurso pedagógico y la praxis educativa, dando lugar a una educación alejada del contexto en el que se ve envuelto la 
existencia del ser humano histórico. La sombra de la Ilustración es demasiado alargada y se ha hecho presente en la forma y estilo de vida de Occidente, conformando sus instituciones, organizaciones sociales, leyes... Nada ha escapado a su influencia, tampoco el sistema educativo. Levinas propone otra manera de entender al hombre y su relación con los demás y con el mundo, distinta de la filosofía cartesiana que establece una dualidad irreconciliable entre pensamiento y mundo, como si se tratara de dos ámbitos diferentes y opuestos; presupone la existencia de un reino ontológico distinto de la existencia humana. Levinas plantea otra antropología que sitúa al ser humano en su circunstancia, dentro de la historia, no por encima o al margen de ella. Desde esta perspectiva, entiende al ser humano condicionado por su corporeidad, su vulnerabilidad y contingencia. Somos, necesariamente, circunstancia, contexto, experiencia; y fuera de la circunstancia, el ser humano es ininteligible.

Hemos nacido casualmente en un mundo, en un universo simbólico, en un tejido de historias, de costumbres, de hábitos, de ritos, de mitos..., todo lo que constituye nuestra gramática. Esta no es algo añadido a otra cosa 'substancial', sino que, como la biología, está inscrita en nuestro 'modo de ser' ab initio, sin embargo, la realidad humana no se reduce a su herencia biológica y cultural. Hay vida humana (e inhumana) porque además de naturaleza heredada el ser humano posee condición. (Mèlich, 2010, p. 39).

Levinas propone, además, otra ética que se traduce en responsabilidad y acogida al otro, como respuesta a la demanda inapelable del rostro necesitado del otro. Y esta respuesta no solo a quien comparte con nosotros un mismo espacio (nuestros conciudadanos), sino también a aquellos que nos han precedido (ética de la memoria) y a los que vendrán detrás de nosotros. De este modo, antropología y ética, constituyen los dos grandes ejes en los que necesariamente se desenvuelve la acción educativa. Si la existencia del hombre discurre dentro de las coordenadas de un tiempo y un espacio concretos, la acción educativa no se puede apartar, ni puede prescindir de aquello que la sustenta, de su soporte básico.

Levinas construye una nueva antropología que no nace de una consideración metafísica del ser humano, sino de su realidad corpórea, y, por tanto, desde el tiempo y el espacio, desde la contingencia y la memoria, desde la finitud y la alteridad. Levinas se aparta de la concepción platónica del hombre y de la ética y antropología kantianas. Para él, el ser humano es un ser habitado por otro del que no puede desprenderse sin poner en riesgo su propia identidad. La estructura antropológica del hombre está quebrada por la presencia del otro. Esta radical alteridad, que constituye al ser humano, produce un profundo extrañamiento. En la antropología levinasiana

el modo propio de ser del hombre más que ser con el otro (mit sein) es un ser para el otro, que no se explica desde sí y en sí, sino desde el otro, en una clara relación asimétrica que prescinde o ignora toda relación de reciprocidad entre el yo y el tú. (Ortega, 2016, p. 251; cursiva del original). 
Levinas lo expresa en estos términos: «En la prehistoria del Yo, puesto para sí, habla una responsabilidad. El sí mismo, en su plena profundidad, es rehén de modo mucho más antiguo que es Yo, antes de los principios». (Levinas, 2011, p. 187). Este desgarrón en la misma estructura radical del ser humano, este

tener que 'pasar' por los demás para poder decirse, muestra, así, que el hombre es un ser extrañado de sí mismo; que es un extranjero, en el sentido más radical del término, pues vive en un mundo que le precede y que está habitado ya por otros y, es más, que necesita de ellos para poder decirse. (González-Arnáiz, 2002, p. 131).

Esta dependencia o asignación al otro antes de toda elección Levinas la expresa así: «El rostro del prójimo significa para mí una responsabilidad irrecusable que antecede a todo consentimiento libre, a todo pacto, a todo contraton. (Levinas, 2011, p. 150). Somos seres radicalmente necesitados del otro para existir como humanos.

Antes de la presencia interpelante del otro somos, sí, pero pura existencia, sueño prolongado. El otro es el que nos saca de nuestro autismo y nos convierte en seres vivos. No somos seres vivos antes de que el otro interrumpa el continuum o sueño de la existencia vacía. (Mate, 2011, p. 39).

En Levinas el sujeto se constituye en lo que no es, en lo que no le pertenece. Es un sujeto "hipotecado» en la radicalidad de su misma existencia. "En rigor el otro es 'fin' porque yo soy rehén, responsabilidad y substitución que soporta el mundo en la pasividad de la asignación, que llega hasta la persecución acusadora, indeclinable». (Levinas, 2011, p. 201).

Levinas elabora, además, una nueva ética. Para él, la ética es responsabilidad, responder de algo ante el otro o del otro, hacerse cargo de él. "El prójimo me concierne antes de toda asunción, antes de todo compromiso consentido o rechazado. Estoy unido a él que, sin embargo, es el primer venido sin anunciarse, sin emparejamiento, antes de cualquier relación contratada». (Levinas, 2011, p. 148). La responsabilidad en Levinas es pura pasividad. Ser responsable ante el otro no es un ejercicio de reflexión, ni es un deber que se impone desde fuera, ni desde dentro de mí. Mi responsabilidad ante el otro supone un vuelco tal que no puede entenderse más que como un cambio de estatuto de mí.

La responsabilidad para con el otro, que no es el accidente que le adviene a un Sujeto, sino que precede en él a la esencia, no ha alcanzado la libertad donde habría adquirido el compromiso para con el otro. No he hecho nada y siempre he estado encausado, perseguido. (Levinas, 2011, p. 183).

La ética no es una doctrina, un conocimiento, un código de buenas conductas.

Es un evento, el evento fundador del 'sí mismo', desde y en que cada singularidad existente...se instala como sujeto encarnado, un evento de apertura radical a la exterioridad, al afuera, un evento de trascendencia en el que la 'identidad' de los sujetos es ya, desde siempre, una 'identidad' hipotecada, dependiente. (Pinardi, 2015, p. 650). 
La ética en Levinas es vivir con la mirada puesta en el otro para responder a su demanda; es prestar atención a la voz del otro que llevamos dentro; ese otro del que no nos podemos separar. Pero el otro se nos presenta

por la mediación de la forma corporal, a partir de la envoltura carnal que se sitúa ante mis ojos y me revela la existencia de los otros, al igual que mi propio cuerpo comparece en el mundo y fundamenta mi ser para-otros. (Fernández-Guerrero, 2019, p. 172).

El otro se me hace presente como un ser sufriente, no como una representación ideal del dolor. El otro, en Levinas, tiene rostro. La ética para él, es compadecerse del otro, es compasión.

Se trata de decir la identidad misma del yo humano a partir de la responsabilidad, es decir, a partir de esa posición o de esa deposición del yo soberano en la conciencia de sí, deposición que, precisamente, es su responsabilidad para con el otro. La responsabilidad es lo que, de manera exclusiva, me incumbe y que, humanamente, no puedo rechazar. (Levinas, 2015, p. 85).

La ética es obedecer al mandato inapelable del otro desde la autoridad de su miseria y desnudez, desde su sufrimiento, sin que yo pueda hacer oídos sordos a su llamada. Es un encuentro, un acontecimiento inesperado que nos sorprende y nos trastorna porque hemos de hospedar a alguien con el que no habíamos contado. Y no nos es permitido situarnos al margen de la ética si no queremos poner en riesgo nuestra misma identidad como humanos. Es nuestra servidumbre y, paradójicamente, nuestra "grandeza». La condición de rehén del otro lejos de degradar al hombre, le dignifica al convertirlo en sujeto responsable, es decir, ético. Ser ético es la condición para su misma existencia como humano, y esta misma condición es la que favorece la posibilidad y existencia de la educación.

La respuesta responsable al otro se resuelve siempre en la acogida, en el hacerse cargo del otro necesitado, como el buen samaritano; es plena disposición (heme aqui) ante la presencia vulnerable del otro. Es compasión. Esta experiencia original, única, es una manifestación (epifanía) del otro en la vulnerabilidad de su rostro, en la realidad de su existencia. En adelante, ya nada será igual para ambos, el que acoge y el acogido. Han entrado en una nueva forma de vida del uno para el otro "de gratuidad total, que rompe con el interés; un para de la fraternidad humana al margen de todo sistema preestablecido». (Levinas, 2011, p. 161; cursiva del original). Desde la ética de la compasión, el que compadece no se pregunta qué "debo hacer", sino "de quién soy prójimo»; no es la obligación de responder por un imperativo formal, sino por la "autoridad" de la persona concreta necesitada que me demanda una respuesta inapelable; es la imposibilidad de cerrar los oídos a la voz interior que nos dice y nos manda: "No Matarás» al otro que sale a tu encuentro. La ética es la atadura compasiva que nos liga al otro sin que podamos librarnos de él. A diferencia de la ética formal kantiana, la ética levinasiana tiene un contenido material referido a la respuesta concreta que damos a las distintas situaciones en las que el ser humano se ve interpelado por el otro necesitado. 
En este acontecimiento (ético) no sale a nuestro encuentro la 'naturaleza humana' del otro, ni su cultura o identidad Ni siquiera la idea de dignidad del hombre, sino la realidad concreta, histórica del otro, la vulnerabilidad del pobre reflejada en el rostro, la radical necesidad del hombre finito abocado a la muerte. La ética no acontece en el mundo de los universales abstractos, sino en la comunión de los hombres y mujeres concretos. (Ortega y Romero, 2019, p. 160).

La ética, más que discurso o argumento, es, ante todo, un quehacer compasivo; y no tiene como referente exclusivo al ser humano físicamente necesitado, ultrajado, no se reduce a un dato estadístico. Ser compadecido es la condición estructural del ser humano. Pero la ética no nos libra de la perplejidad e incertidumbre que acompañan a todo ser humano, no nos despoja de nuestra condición de nómadas, nunca afincados a un "territorio moral" seguro, ni nos garantiza una respuesta acertada.

La ética no nos asegura la paz de la conciencia, la tranquilidad del deber cumplido. La ética es inseparable del riesgo, de la incertidumbre. No nos lleva a meta alguna previamente fijada. Todo está por construir, todo es provisional como la "circunstancia» (situación) que envuelve la vida misma; no hay cánones prefijados que prescriban una conducta, la tenemos que realizar «a tientas», sin más argumentos que aquellos que brotan de los sentimientos de compasión. En todo momento nos sentimos inmersos en la improvisación, en la aventura y el riesgo de no ser lo suficientemente compasivos.

No hay (ni puede haberla) una respuesta ética definitiva porque los humanos, por naturaleza seres nómadas, vivimos siempre en despedida; no hay tampoco una respuesta educativa definitiva y universal, esta será siempre una respuesta única, singular, propia de la singularidad y excepcionalidad del ser humano. (Ortega, 2016, p. 255; cursiva del original).

La seguridad y la certidumbre éticas no forman parte del equipaje del ser humano.

El adverbio habla de nuestra condición: contingente, finita, enraizada en un tiempo $\mathrm{y}$ en un lugar concretos. Al principio era el adverbio porque desde el principio el ser humano se encuentra condicionado. Porque desde el principio el ser humano es un ser finito. (Mèlich, 2018, p. 8).

Esta condición adverbial desautoriza cualquier concepción idealista, metafísica del ser humano. Corporeidad, finitud, contingencia hacen que el ser humano tenga que improvisar constantemente la respuesta ética al otro.

Desde estos presupuestos éticos y antropológicos, la educación se configura como el comienzo de algo nuevo, haciendo de la experiencia de vida del alumno contenido imprescindible del proceso educativo. Esta nueva concepción hace necesario otro modo de educar y otra fuente de pensamiento como soporte de la praxis educativa. 


\section{LA EDUCACIÓN ES UN NUEVO NACIMIENTO}

Si la ética es una respuesta compasiva a un sujeto singular, en una situación de necesidad, la educación, en tanto que respuesta ética del educador al educando, es también una experiencia, una respuesta singular, un encuentro único e irrepetible con el otro necesitado de acogida y acompañamiento. Este encuentro con el otro marca un nuevo nacimiento. Es un acontecimiento único que pone en marcha todos los resortes de una nueva existencia.

Al igual que no sabemos por qué y cómo se produce la respuesta compasiva hacia el otro necesitado. Es algo "misterioso", llega a decir Schopenhauer (1993, p. 254), tampoco sabemos cómo se produce y por qué la acción de acogida y acompañamiento al otro en un proceso educativo. Podemos establecer las «condiciones» para que dicho encuentro ético se produzca, pero la experiencia del mismo no está a nuestro alcance. ¿Qué ha acontecido en el educador que le ha hecho salir de sí para acoger al otro?, ¿cómo ha influido en el educador la presencia del otro?, ¿qué ha acontecido en el educando al confiar en el otro, dejarse acoger y acompañar por él?, ¿qué ha supuesto en la vida del educando la figura ética del educador? Solo podemos afirmar que, en la educación, como acto y como proceso, se produce un encuentro, un acontecimiento ético que marca el comienzo de algo nuevo, la experiencia de una nueva existencia, pero siempre quedan muchas preguntas sin respuesta. La dimensión ética que envuelve a la educación no permite un conocimiento "acabado" del proceso educativo.

La educación es siempre el comienzo de algo nuevo: nunca puede ser la repetición de lo ya dado. Cada acción educativa es para el educando una nueva situación, una nueva ocasión de responder a la actitud de acogida del educador. En la educación acontece el "milagro" de la epifanía de un nuevo ser, una nueva experiencia que se manifiesta en una manera nueva, singular y única de realización del ser humano. «(...) lo nuevo siempre aparece en forma de prodigio. El hecho de que el hombre sea capaz de actuar significa que cabe esperarse de él lo inesperado, que es capaz de realizar lo que es infinitamente improbable». (Arendt, 1993, p. 202) Esta experiencia inédita, "misteriosa» constituye una aportación nueva al mundo en construcción, y tiene para la educación consecuencias inevitables, dando entrada a la sorpresa, a la improbabilidad, a la natalidad o nuevo nacimiento. Erróneamente hablamos de la adquisición de "competencias" para la apropiación de valores, ignorando que estos, por su propia naturaleza, escapan a un control que lo harían extrapolable a los procesos instructivos. La ética, en tanto que respuesta compasiva al otro necesitado, es siempre singular, única e irrepetible. "La ética no es la moral, sino su punto ciego porque emerge en un escenario en el que 'el marco normativo heredado' es puesto en cuestión. La ética surge en una situación-límite, en una situación de radical excepcionalidad». (Mèlich, 2010, p. 90; cursiva del original). La educación, como respuesta de acogida al otro, comparte con la ética esta característica de ser, también, una actuación singular, única, original, porque no hay, 
ni puede haberla, una acción educativa que sea igual para todos. Cada individuo vive en una circunstancia que le condiciona de un modo singular; y cada individuo interpreta $s u$ mundo también de un modo singular.

Ello obliga a abordar la educación con herramientas distintas a las que se emplean en otros ámbitos del saber. En educación, muy a menudo, se nos escapa aquello que llevamos entre manos: el ser humano. En un proceso educativo solo podemos asistir al nacimiento de algo inesperado que, hasta ahora, solo era promesa y empieza a ser realidad por el encuentro ético entre dos que se reconocen (educador y educando) en la salida de sí mismos para construir una nueva realidad: el comienzo de algo nuevo. Esta nueva realidad, por su carácter singular, original, reclama también un tratamiento singular y original. Exige una pedagogía del nacimiento como forma de recibir a los que llegan a nuestro mundo y al suyo, siempre en construcción, desde la radical alteridad del otro nunca asimilable al yo; y una pedagogía del comienzo que incorpora y transforma lo antiguo para integrarlo en un nuevo proyecto de realización de cada ser humano.

La pedagogía del nacimiento y del comienzo conlleva un cambio profundo en el discurso pedagógico y en la praxis educativa. Con frecuencia los educadores han proyectado sobre los educandos nuestro ideal de vida sin prestar atención a los intereses y necesidades de aquellos a quienes pretendemos acompañar en su proyecto de realización personal. Y solo desde la atención al otro, desde la experiencia de la vida del otro, se inicia un proceso de acogida y acompañamiento, un proceso educativo. La praxis heredada de una educación "por encargo", hecha a distancia, nos ha alejado de cualquier posibilidad de educar para convertirnos en instrumentos involuntarios de un solapado adoctrinamiento. Una educación "transmisora" de saberes, conocimientos y competencias no ha posibilitado a los educandos la inserción creativa en su mundo, su modo particular de «estar en el mundo y con los demás». La función de "transmitir» nuestro legado cultural a las nuevas generaciones ha eclipsado el deber inexcusable de prestar atención y escuchar la vOz de la experiencia de cada educando, el relato de su vida. Y solo se educa cuando se escucha y acoge la palabra del otro "que nos trasciende como educadores y frente al cual tenemos la obligación de asumir una responsabilidad incondicional, más allá de todo contrato posible o reciprocidad». (Bárcena y Mèlich, 2000, p. 35); solo se educa desde la experiencia distinta de cada educando. Este es un principio vertebrador de toda acción educativa.

\section{LA EXPERIENCIA DEL ALUMNO, CONTENIDO EDUCATIVO}

Solo es posible la existencia del ser humano en su circunstancia, en su situación. No hay existencia sin circunstancia. Y solo es posible la educación si se tiene en cuenta al ser humano que existe en $s u$ circunstancia, no a una imagen ideal del mismo. Hacer de la circunstancia, de la experiencia de vida del alumno contenido educativo implica asumir al hombre como un ser histórico, lejos de la imagen «ideal» 
heredada de la filosofía platónica. El error de la pedagogía cognitiva, idealista es que solo ha tenido como referente antropológico y ético la explicación individualista e ideal del ser humano, ignorando otras interpretaciones que lo definen como un ser situado, abierto al otro. La deriva idealista ha eclipsado al hombre de carne y hueso, ocultando sus atributos esenciales: corporeidad, vulnerabilidad, finitud, resaltando otros como el pensamiento, que lo diferencian radicalmente de los otros seres. La experiencia nos dice que «el ser humano lleva dibujado en su rostro las señales de la finitud, de lo contingente, de la enfermedad y de la muerte. Este es un hecho de la experiencia, no una ficción». (Ortega y Romero, 2019, p. 147).

La condición inevitable del ser humano de ser habitante de una cultura, de una tradición, anclado a un contexto o situación expresa mejor que ninguna otra figura la tensión a la que está sometido el discurso pedagógico que debe "dar cuenta" de la constitución de su propio discurso, y al mismo tiempo estar referido al discurso de los demás. No hay existencia y luego la situación. La situación

está de tal modo dentro de mí que la experimento como aquello donde yo estoy. Ella es un lugar, porque solo me encuentro cuando regreso a ella, al igual que me sitúo a mí mismo en la reflexión concéntrica que parte de la totalidad de las circunstancias. (Rombach, 2007, p. 147; cursiva del original).

Tratar de eludir la "circunstancia" supone renunciar a educar, pues siempre se educa a alguien, sujeto histórico que vive necesariamente en una circunstancia.

Es ahí, en la sustantiva circunstancia, donde se resuelve a diario la existencia humana. Y es ahí, en la inevitable circunstancia en la que hay que educar, porque no en otro mundo distinto a la situación o circunstancia habita el otro de quien se debe responder. (Ortega, 2016, p. 254; cursiva del original).

No hay una educación contextual o situada y otra que no lo sea. Prescindir de esta "condición" es abocar al fracaso a cualquier acción educativa. Por ello se hace imprescindible contar con la experiencia de cada educando como punto de partida y de llegada en un proceso educativo.

La pedagogía cognitiva se ha servido de la experiencia como un mero recurso o estrategia para el aprendizaje de conocimientos o destrezas, pero nunca se la ha considerado como contenido educativo. La experiencia de vida de cada educando, su historia y contexto eran sistemáticamente ignorados. Y una educación irreal que "pasa por alto" la condición histórica del ser humano, su experiencia de vida, no puede dar respuesta a la pregunta que inevitablemente todo humano se hace: quién soy yo y cuál es mi relación con el mundo y con los demás. La pedagogía cognitiva, al prescindir de la experiencia, se ha visto obligada a utilizar el juicio moral como estrategia adecuada (y única) para promover y facilitar una conducta moral, según la ética kantiana. Una concepción del hombre sesgada, mutilada no puede dar cuenta de cómo responde a la demanda del otro en su situación concreta. Desde este modo idealista de pensar no es el ser humano corpóreo, vulnerable de quien debemos 
responder, solo un ente universal, imaginario al que le suponemos dignidad. Desde la ética, respondemos del ser humano en su condición de ser necesitado, no de otro que, desde la imaginación, nos hemos inventado.

Pero ¿se puede enseñar a responder éticamente al otro necesitado? Si la respuesta ética, es decir compasiva, es siempre imprevista, original e irrepetible, se hace difícil aceptar el aprendizaje de competencias o consistencias que capaciten al educando para responder habitualmente al otro necesitado en una situación concreta. El carácter singular, único e irrepetible de la respuesta compasiva escapa a toda posibilidad de adquirir una competencia específica para su realización. No somos competentes para una respuesta ética, la debemos improvisar constantemente. Nunca estamos suficientemente preparados para una respuesta compasiva. La mirada ética entra en el ámbito de los afectos, de los sentimientos.

Una ética de la compasión no puede ser sino una ética de los afectos y no de los efectos, una ética de la afectividad y de la intimidad, no de las grandes respuestas establecidas de antemano, ni de los códigos deontológicos. Una ética de la compasión es una ética de la sensibilidad con el otro. (Mèlich, 2010, pp. 132-133; cursiva del original).

Si bien podemos hablar de itinerarios o estrategias que faciliten la adquisición de hábitos o destrezas para la realización de determinadas conductas como el razonamiento moral, el cumplimiento de las normas de convivencia, desarrollo intelectual... aprender, en cambio, a compadecerse del otro se torna una tarea que no se atiene a los cánones del aprendizaje de hábitos. El carácter singular, único y original de la respuesta compasiva no lo hace posible. Si existe vida ética, entonces no hay ni podrá haber nunca competencias éticas.

Por ello, más que enseñar competencias o hábitos que faciliten una conducta ética, habría que promover en los educandos el desarrollo de actitudes de acogida y de empatía hacia el otro en sus circunstancias concretas. Este tipo de aprendizajes requiere acudir a la experiencia de vida de cada educando a través de la narración o el relato, y que sea esta experiencia la que se convierta en contenido y estrategia educativa. La narración constituye un medio privilegiado para transmitir la experiencia educativa, como experiencia de vida. El conocimiento pedagógico constituye también una narración «y por eso es necesario definirlo también desde su capacidad para describir la experiencia subjetiva de las personas en función del sentido que estas le dan a las mismas». (Vila, 2008, p. 2).

La narración nos desvela lo que hemos sido y hemos vivido, lo que somos y lo que hoy vivimos, es decir, la experiencia de nuestra vida. "En realidad, nuestras 'historias' constituyen el resumen o el precipitado vital y narrativo de las sucesivas asociaciones de espacio y de tiempo que hilvanan el tejido de toda nuestra existencia humana». (Duch, 2004, p. 165). La narración es un libro que se abre para ser leído por otros. "Las propias experiencias pueden ser posibles experiencias de otros y también que las experiencias de los demás pueden ser posibles experiencias propias». (Van Manen, 2003, p. 75). Las experiencias narradas no suelen ser relatos 
de episodios esporádicos que accidentalmente ocurrieron, sino acontecimientos vinculados con vivencias, creencias, valores y expectativas de sus protagonistas. Tienen por ello un alto valor educativo.

A partir de las historias o relatos narrativos podemos inferir los motivos... que conducen a los alumnos a actuar de una determinada manera y los elementos... que en un momento concreto pueden limitar o favorecer las posibilidades para desarrollar una determinada conducta o comportamiento dentro del contexto escolar. (Mateos y Núñez, 2011, p. 120).

En la experiencia narrada la alteridad es despojada de su carácter genérico y abstracto para encarnarse en alguien concreto, con nombre y apellidos, "el extranjero, el huérfano y la viuda», en expresión de Levinas, que demanda de nosotros una respuesta responsable. Y en esa lectura, la experiencia narrada ya no es solo mía, es también de los otros al ser evocada.

El otro puede aprender de mi experiencia a condición de que él mismo haga la suya... porque el objetivo del narrador no es comunicar un hecho (esta sería la información), sino la transmisión de una experiencia y el darse él mismo en el testimonio, para que aquellos que reciben la transmisión puedan rehacerla y puedan aprender. (Mèlich, 2002, pp. 82-83).

En la narración la experiencia no se repite, se evoca, se hace presente en un nuevo contexto, y al evocarla, se le da nueva vida, es reinterpretada. "Las personas, a través de sus historias, vuelven a revivir momentos significativos no solo desde el punto de vista descriptivo..., sino también entrando de nuevo en el paisaje emocional de las vivencias narradas». (Mateos y Núñez, 2011, p. 113). La narración de la experiencia sitúa al educando en el centro de su proceso educativo. Es su experiencia, su vida contada, experiencia que como escribe Gadamer (1993, p. 97) es la vivencia de uno mismo: «Lo vivido es siempre vivido por uno mismo... no es algo que fluya y desaparezca en la corriente de la vida de la conciencia». No es la experiencia y vida de unos modelos ideales, traídos de la leyenda y la literatura, la que se convierte en experiencia ética. Son experiencias cercanas, sujetas a contradicciones, que reflejan la vida real de individuos también reales. La narración nos desvela quiénes somos y cómo hemos llegado hasta aquí. Nuestra existencia es narrativa. "Nuestra vida no es solo un discurrir de situaciones que se suceden, sino que vivimos nuestra vida contándonosla. Nuestra vida es, indisociablemente, experiencia de vida". (Pérez Guerrero, 2016, p. 229). Responder a la pregunta "¿quién soy?» "Es contar la historia de una vida. La historia narrada dice el quién de la acción. Por tanto, la propia identidad del quién no es más que una identidad narrativa». (Ricoeur, 1996, p. 997; cursiva del original). La experiencia en la educación deja de ser un mero recurso didáctico para convertirse en contenido educativo esencial.

Implementar la pedagogía narrativa conlleva la creación de un clima de confianza en el aula que facilite la expresión libre de las experiencias vividas por los educandos. Ello exige en el educador: 
a) atender, escuchar las inquietudes y necesidades de los educandos. El educador no puede ser un muro contra el que tropiecen las incesantes preguntas que surgen de las experiencias de cada educando. Escuchar la voz del otro se hace indispensable si se quiere acompañar y no abandonar a su suerte al educando.

b) salir de sí mismo, ponerse en el lugar del otro, haciendo que el proceso educativo sea un espacio de encuentro entre educador y educando, desde la experiencia vivida por cada educando.

c) crear un clima de empatía y proximidad en el aula que permita entre los educandos la expresión libre de sus experiencias. Pero no podemos reducir la empatía a un simple reconocimiento «intelectual» de la dignidad del otro. Es necesario un abordaje desde la ética, es decir, desde la compasión.

d) generar relaciones de responsabilidad entre los educandos. La vida y conducta de cada uno tiene repercusiones en la vida del otro. Nadie nos es indiferente. De este modo, la experiencia narrada por uno puede ser interpretada como una experiencia compartida por los demás.

e) integrarse en esta dinámica de confianza y responsabilidad del aula. El educador también tiene experiencias que contar que pueden ayudar a los educandos a descubrir el lado humano de su profesor. Sus éxitos y fracasos, las dificultades de su vida pueden y deben ser llevadas al aula. Solo así se evitará que el profesor sea visto por los alumnos como alguien extraño, ajeno a lo que se vive en el aula.

La pedagogía narrativa es también una pedagogía de la memoria. El relato de nuestra identidad no lo podemos construir sobre el vacío, sino sobre la memoria. El ser humano es un ser de memoria, construye sobre el pasado. Lo que somos hoy hunde sus raíces en lo que otros fueron antes que nosotros. Pero hacer memoria no es un ejercicio romántico, es una condición inexcusable para entender el presente. "Nuestro modo de instalarnos en el mundo y de relacionarnos con los demás, lo que ahora somos y cómo vivimos no se puede entender sin el legado de los otros que nos han precedido». (Gárate y Ortega, 2013, p. 174). Llevar la memoria a las aulas es hacer que la experiencia de nuestra vida se haga más transparente a nosotros y a los demás. Contar cómo hemos llegado hasta aquí es reconocer la deuda siempre pendiente con los que nos han precedido. No somos un eslabón perdido en la cadena humana.

Cada individuo es el fruto de una historia; no es el resultado de la aplicación de un plan o programa previo, sino un constante comienzo... La condición de persona no es una entidad fija dada de una vez por todas, ni una identidad sustancial. Es una narración - un nacimiento y un devenir - a partir de una trama de relaciones humanas, políticas y sociales. Significa insertarse en una historia que nos precede, un relato que nos forma 
y del que cada uno aprende a distanciarse al crear su propia biografía. (Bárcena, 2005, pp. 135-136).

\section{OTRO MODO DE EDUCAR}

La pedagogía basada en la experiencia del alumno obliga a los pedagogos y educadores a reflexionar sobre la necesidad de implementar "otro modelo" de educación que la aleje de la filosofía idealista que ha prescindido de la experiencia de vida del alumno en los procesos educativos. El modelo educativo, basado en la antropología y ética levinasianas que proponemos, implica una actuación en torno a los siguientes ejes:

a) Abandono del pensamiento idealista. El discurso pedagógico y la praxis educativa se han alimentado del pensamiento idealista de la Ilustración que le han impedido encontrar el modo de hacer suya la situación en la que vive cada educando. Se ha construido un discurso pedagógico sobre una idea del hombre alejada de la realidad de lo que el ser humano es.

El dar más importancia a la idea que uno se hace del hombre que a lo que el hombre es en realidad, es un gesto típicamente idealista, un vicio ese con el que la filosofía se ha recreado irresponsablemente durante demasiado tiempo. (Mate, 2018, p. 108).

Ello ha propiciado una educación a-pática, irreal que no responde a las necesidades e intereses de cada educando. Se ha potenciado una educación "racional", olvidando los sentimientos y los afectos, la vida real de cada educando. Y sin incorporar la experiencia del educando al proceso educativo, la educación se convierte en una actuación sobre individuos ideales, imaginarios, sin historia ni contorno. La filosofía idealista ha tratado a la educación como una eficaz herramienta para el encaje del educando en el entramado social; se ha perdido de vista al ser humano concreto, sujeto y protagonista de su proceso de formación; se ha pensado la educación como repetición de lo dado y no como innovación y búsqueda de otros modos de «estar en el mundo" y hacerse cargo de él; se ha ignorado que en la educación empieza algo inédito como forma original de «estar en el mundo», y con él una nueva aportación a su construcción desde los parámetros de la justicia y la compasión.

b) Compromiso social y político. La pedagogía basada en la experiencia ética tiene necesariamente una dimensión política y social. Implica la crítica a un modelo de sociedad que impide la construcción de una sociedad humanizada. "De todas las funciones que se le presuponen a la educación, una de las más relevantes y necesarias es colaborar en la construcción de una ciudadanía humanizada». (Pallarés, 2020, p. 10). De no ser así, «la educación ya no podría cumplir con su propósito". (Jordán y Codana, 2019, p. 35). Poner en relación la ética de la compasión con la bumanización de la sociedad significa que ser compasivo implica no poner límites a nuestra responsabilidad, asumir la responsabilidad del otro más allá del derecho o la norma. 
La necesidad de ordenar la vida en sociedad según normas jurídicas ha limitado la responsabilidad ético-moral al marco estrictamente jurídico. Con ello se ha vaciado de humanidad, de gratuidad y solidaridad las relaciones interpersonales, y se ha instalado en la sociedad la globalización de la indiferencia. (Ortega y Romero, 2018, p. 110; cursiva del original).

La expresión levinasiana "el extranjero, el huérfano y la viuda" son figuras simbólicas del otro sufriente, marginado, del «Sobrante» en nuestra sociedad. Son figuras literarias del "tercero» del que nos habla Levinas en sus textos.

c) Atención al ser humano bistórico. Educar exige asumir todo lo bumano, todo lo que envuelve la vida del otro. No se educa a seres imaginarios, sino a individuos concretos, dentro de la historia, no al margen o por encima de ella, al ser humano condicionado, por su corporeidad, su vulnerabilidad y su contingencia. Todos pertenecemos al colectivo de los «extranjeros, huérfanos y viudas» de los que habla Levinas para expresar, a través de estas figuras, la vulnerabilidad, la fragilidad de todo ser humano, necesitado de compasión. El hombre es un ser necesitado del otro, estructuralmente necesitado de compasión. El hombre es, en sí mismo, necesidady demanda de compasión (Ortega y Romero, 2019, p. 147). De este ser humano se ocupa la educación, un ser «naturalmente» desprotegido, sin más apoyo que los lazos que le unen a su comunidad; que para seguir viviendo se ve obligado a inventar nuevas formas de existencia en su interminable carrera por adaptarse y transformar su medio. Cualquier otro sucedáneo de hombre se aleja de su realidad histórica.

d) Presencia de la compasión. Nuestra propuesta educativa concibe la educación atravesada por la ética, y no como objetivo de la acción educativa, como algo que le venga de "fuera", sino como elemento constitutivo de la misma. La ética está en la entraña misma de la acción educativa, es su seña de identidad. La pedagogía basada en la experiencia demanda la ética de la compasión como modo de hacerse cargo del otro; es del todo ajena a la ética formal kantiana que "pasa por alto" la situación concreta del educando, su experiencia de vida. La ética de la compasión es una responsabilidad sin límites hacia el otro y se traduce siempre en acogida y hospitalidad, "en la que la relación con el otro no es una relación contractual o negociada, sino ética, responsable, en la que el 'yo' no es cuidado de sí, sino cuidado del otro". (Ortega, 2013, p. 414; cursiva del original). La responsabilidad en Levinas no pertenece a la conciencia, no es la aplicación de una reflexión que me impele a actuar, ni siquiera es un deber que se impondría "desde fuera o desde dentro". La responsabilidad hacia el otro supone un vaciamiento o desposesión de mí. Es "el hecho para el ser de des-prenderse, de vaciarse de su ser, de ponerse 'al revés'». (Levinas, 2011, p. 186). Es lo que Levinas quiere expresar con el término «rehén».

e) Un nuevo discurso y un nuevo lenguaje. La educación exige una constante renovación en su lenguaje y en su discurso; y hacer de la experiencia ética la circunstancia indispensable en la que se inscribe la acción educativa. Es necesario un nuevo discurso y un nuevo lenguaje que dé la palabra a las experiencias de 
cada alumno, a sus sentimientos y expectativas; un nuevo lenguaje que hable y deje hablar la palabra insustituible, propia de cada alumno. Ello implica asumir la responsabilidad de dar la palabra a los recién llegados

que tienen que tomar la palabra, su propia palabra, esa palabra que es palabra futura e inaudita, palabra aún no dicha, palabra por-venir. Introducir a los nuevos en el lenguaje es, por tanto, hablar y hacer hablar, hablar y dejar hablar. (Larrosa, 2001, p. 79).

Es preciso bajar el telón del «teatro metafísico» en el que se ha instalado el discurso y el lenguaje en la educación, y dar paso a la entrada en escena del ser humano histórico, inexplicable sin los lazos que le vinculan con el mundo y con los demás.

f) Testimonio: Quizás sea la piedra angular de este otro modo de educar. Sin testimonio puede haber enseñanza, pero no educación. Solo se educa cuando los valores que se proponen se traducen en la experiencia del educador. "La relevancia que tiene un filósofo para mí está en función directa de su capacidad para ofrecer un ejemplo... Pero el ejemplo debe ser dado mediante la vida visible y no solo a través de los libros». (Nietzsche, 1996, p. 151). Pero el testimonio se ofrece desde la experiencia precaria, a veces contradictoria, del educador. Ser testigo en educación es asumir la tarea de educar como la respuesta ética que se da al otro del que se es responsable. Implica pasar a un segundo lugar para que el otro (el educando) tenga la primacía.

Un maestro que no se retire para dejar pasar al otro, que no abra y se abra a la interpretación del otro, un maestro que no cuide la palabra viva del otro, lo que hace es adoctrinar, en modo alguno educar. Existe maestría cuando el otro puede nacer diferentemente a su maestro, y cuando la relación maestro-discípulo llega a ser una relación deferente, solícita, responsable. (Mèlich, 2002, pp. 53-54).

\section{OTRA FUENTE DE PENSAMIENTO: DEL LOGOS AL PATHOS}

Para los sociólogos, una de las características más acentuadas de la sociedad occidental desarrollada es la atomización de los individuos. Se han debilitado hasta el extremo los lazos de afecto y proximidad, de fraternidad y solidaridad. Pero este "proceso de deserción no es en modo alguno el resultado de un déficit cualquiera o de una carencia de sentido... el deambular apático debe achacarse a la atomización programada que rige el funcionamiento de nuestras sociedades». (Lipovetsky, 2000, p. 42). La frialdad que caracteriza a esta sociedad se ha convertido en un "universal antropológico", en un elemento constitutivo de la vida social. Las relaciones sociales han pasado a convertirse en relaciones meramente pragmáticas. El resultado es un conglomerado de individuos aislados, inmersos en un mundo de frialdad, incapaces de revertir esta situación. Es una sociedad que ha hecho del miedo y la impotencia armas «legítimas» para su propia supervivencia (Beck, 1998). 
También la filosofía moderna ha contribuido a esta frialdad que caracteriza a la sociedad actual al dar "por sentado que la constitución monadológica del Yo era una entidad originaria, al margen de toda socialidad y aislada del mundo y de los otros». (Maiso, 2016, pp. 56-57).

¿Qué puede hacer la escuela en esta situación? No debemos pedir al sistema educativo que sea el "salvador" de la humanidad, pero sí puede y debe ser la conciencia crítica de aquellas situaciones que degradan y ofenden a la dignidad del ser humano. Es la sociedad o tribu quien educa, pero en ella la escuela desempeña un papel relevante como espacio de diálogo y de entendimiento. La convivencia "civilizada" entre todos se construye si dentro del sistema educativo se genera un clima democrático de convivencia, de reconocimiento del otro en su singularidad y diferencia, en su libertad para pensar y vivir de acuerdo con sus creencias y valores culturales. Es decir, una acción educativa que tenga al ser humano como centro y meta del proceso educativo.

Por ello, consideramos necesario acudir a otra fuente de pensamiento que dé cuenta de la totalidad del ser humano que no es solo razón (logos), sino también los sentimientos (pathos). La influencia de la Razón en el devenir de la historia no pocas veces ha tenido resultados contrarios a la razón (Horkheimer y Adorno, 1994). Pero también, en momentos de la historia, la dialéctica de la razón ha significado que la libertad se haya convertido en el reino de la barbarie (Auschwitz). El Estado de la Razón y la Razón de Estado se entretejen a lo largo de la historia.

Este siglo ha fracasado trágicamente en dar a los hombres el sentido de lo humano. Por ello es por lo que, en un mundo que ha heredado, en rebeldía o en aquiescencia, esas épocas de barbarie, y queda desde ellas tentado por el nihilismo y todas las formas, sutiles o brutales, de la desesperación, se hace necesario reavivar la memoria de otra fuente de sentido distinta de la racionalidad griega. (Chalier, 1995, p. 23).

Levinas abre una nueva vía de pensamiento. Para él, la filosofía occidental se asienta sobre la primacía del ser y de la identidad, reduciendo la filosofía a la ontología. Ante esta filosofía de la inmanencia, que cierra toda posibilidad de abrirse al otro y niega toda trascendencia, establece la necesidad de "salir del ser» por una vía nueva.

No se trata de asegurar la dignidad ontológica del hombre como si la esencia fuese suficiente para la dignidad, sino, por el contrario, de poner en entredicho el privilegio filosófico del ser, de preguntarse por lo más allá o lo más acá. (Levinas, 2011, p. 64).

La Razón ilustrada muestra una tendencia irresistible al totalitarismo, a reducir la pluralidad a la unidad, la diferencia a lo mismo.

Es el pensamiento que viene de Atenas en el que prima la especulación sobre la experiencia, como si el pensar fuera una luz con la que se ilumina la realidad gracias a la mirada omnicomprensiva del sujeto. Es la voluntad de someterlo todo al logos. (Ortega, 2004, p. 253), 
olvidando que la existencia de las cosas se da en forma laberíntica, desordenada, irreductible a los discursos de la razón (Goicoechea y Fernández-Guerrero, 2014).

La filosofía griega define el modo de pensar de Occidente: una filosofía de la identidad, de la mismidad, que no solo no deja lugar a la alteridad, sino que es alérgica a ella. Levinas rompe con la tradición metafísica de occidente que va de Parménides a Hegel.

La filosofía occidental ha sido muy a menudo una ontología, una reducción de lo Otro al Mismo, por mediación de un término medio y neutro que asegura la inteligencia del ser. Esta primacía fue la lección de Sócrates. No recibir nada del Otro sino lo que está en mí, como si desde toda la eternidad yo tuviera lo que me viene de fuera. (Levinas, 2002, p. 67).

En Levinas, el ser humano no es una idea universal, un ente abstracto, sin contexto; por el contrario, es tiempo, espacio, circunstancia, situación, experiencia, historia. No se acerca al ser humano desde la ontología, sino desde la ética como filosofía primera; es una ética que tiene como referentes a «el extranjero, el huérfano y la viuda" significados en el rostro sufriente del otro.

La necesidad de acudir a otra fuente de pensamiento implica "pensarnos de nuevo", poner en cuestión las vigas maestras que sustentan lo que hacemos y lo que pensamos. Ello exige vencer las resistencias activas que impiden el cambio. Pero «la mayor resistencia es pasiva, es una forma de pensar que se ha convertido en el hábitat natural. Es esa inevitable trinchera la primera que hay que conquistar». (Mate, 2018, p. 17).

Dice Ortega y Gasset (1975, p. 75) que «no se han hecho en serio las cosas sino cuando de verdad han hecho falta». Una de las demandas más urgentes en educación es tomarse en serio la "circunstancia» o contexto de la acción educativa. Se ha propiciado una educación, si así se puede llamar, idealista y conceptual para situarse en «tierra de nadie».

Sin embargo, del contexto depende que el educador pueda encontrar un espacio de encuentro en el que sea posible establecer una relación ética con el educando; del contexto depende que el educador pueda entrar en el 'mundo' del educando y establecer con él una relación significativa desde un mundo gramatical compartido; del contexto depende que la experiencia de vida del educando juegue un papel básico en la acción educativa; del contexto depende que podamos hablar de educación y no de un juego de artificio. (Ortega y Gárate, 2017, p. 117).

Reivindicar otra fuente de pensamiento en educación significa buscar un punto de encuentro entre el educador y educando en el que sea posible el diálogo entre ambos, convirtiendo la experiencia de vida del educando en el tema «de que hablar». Reconocemos que no es una cuestión fácil cuando la escuela ha estado ausente de la vida de sus alumnos. Estos han sido «objeto o tema» de estudio, pero no sujetos 
de su proceso de formación. La escuela ha pretendido enseñar, pero, no pocas veces, no ha hecho suya la responsabilidad de educar.

Para los autores de este trabajo, Levinas, desde su concepto de hombre (antropología) y de su relación con los demás y con el mundo (ética), constituye una nueva fuente de pensamiento y un soporte teórico sólido para una educación con rostro bumano, haciendo de la experiencia de vida de cada educando, de su situación, el contenido de la acción educativa.

\section{REFERENCIAS BIBLIOGRÁFICAS}

Arendt, H. (1993). La condición humana. Paidós.

Bárcena, F. (2005). La experiencia reflexiva en educación. Paidós.

Bárcena, F. (2018). Maestros y discípulos. Anatomía de una relación. Teoría de la Educación. Revista Interuniversitaria, 30(2), 73-108. https://doi.org/10.14201/teoredu30273108

Bácena, F. y Mèlich, J. C. (2000). La educación como acontecimiento ético. Paidós.

Beck, U. (1998). La sociedad del riesgo. Paidós.

Chalier, C. (1995). Levinas. La utopía de lo humano. Riopiedras.

Duch, Ll. (2004). Estaciones del laberinto. Herder.

Fernández-Guerrero, O. (2019). El dolor como encuentro con la alteridad. Isegoría, (60), 169-188. https://doi.org/10.3989/isegoria.2019.060.10

Gadamer, H. G. (1993). Verdad y método. Sígueme.

Gárate, A. y Ortega, P. (2013). Educar desde la precariedad. Cetys Universidad

Goicoechea, M. ${ }^{a}$ A. y Fernández-Guerrero, O. (2014). Filosofía y educación afectiva en Amor y Pedagogía de Unamuno. Teoría de la Educación. Revista Interuniversitaria, 26(1), 41-58. https://doi.org/10.14201/teoredu20142614158

González, A. (2015). El surgir de la ética. Apeiron. Estudios de Filosofía, (3), 231-247. https:// s3.amazonaws.com/wix-anyfile/fFEhuijjQk2qozSFq5DT_18\%20-\%20El\%20surgir\%20 de\%20la\%20\%C3\%A9tica.pdf

González-Arnáiz, G. (2002). La interculturalidad como categoría moral. En Autor (Coord.), El discurso intercultural (pp. 77- 106). Biblioteca Nueva.

Horkheimer, M. y Adorno, Th. W. (1994). Dialéctica de la Ilustración. Trotta.

Jordán, J. A. y Codana, A. (2019). La influencia del profesor apasionado en la mejora académica. Estudios sobre educación, 36, 31-51. https://doi.org/10.15581/004.36.31-51

Larrosa, J. (2001). Lenguaje y educación. Revista Brasileira de Educaçao, (16), 68-80. https:// doi.org/10.1590/S1413-24782001000100008

Levinas, E. (2002). Totalidad e infinito. Ensayo sobre la exterioridad. Sígueme.

Levinas, E. (2011). De otro modo que ser o más allá de la esencia. Sígueme.

Levinas, E. (2015). Ética e infinito. Machado Edit.

Lipovetsky, G. (2000). La era del vacío: ensayos sobre el individualismo contemporáneo. Anagrama.

Maiso, J. (2016). Sobre la producción y reproducción social de la frialdad. En J. A. Zamora, R. Mate y J. Maiso (Eds.), Las víctimas como precio necesario (pp. 51- 69). Trotta. 
Mate, R. (2011). Tratado de la injusticia. Anthropos.

Mate, R. (2018). El tiempo, tribunal de la historia. Trotta.

Mateos, T. y Núñez, L. (2011). Narrativa y educación: Indagar la experiencia escolar a través de los relatos. Teoría de la Educación. Revista Intertuniversitaria, 23(2), 111-128. https:// revistas.usal.es/index.php/1130-3743/article/view/8648/10639

Mèlich, J. C. (2002). Filosofía de la finitud. Herder.

Mèlich, J. C. (2008). Antropología narrativa y educación. Teoría de la Educación. Revista Interuniversitaria, 20, 101-124. https://revistas.usal.es/index.php/1130-3743/article/view/986

Mèlich, J. C. (2010). Ética de la compasión. Herder.

Mèlich, J. C. (2018). Contra los absolutos. Fragmentos Edit.

Nietzsche, F. (1996). Schopenhauer como educador. En Schopenhauer como educador y otros textos (pp. 139-224). Círculo de Lectores.

Ortega, P. (2004). La educación moral como pedagogía de la alteridad. Revista Española de Pedagogía, 62(227), 5-30. https://revistadepedagogia.org/wp-content/uploads/2007/06/22706.pdf

Ortega, P. (2013). La pedagogía de la alteridad como paradigma de la educación intercultural, Revista Española de Pedagogía, 71(256), 401-422. https://revistadepedagogia.org/ wp-content/uploads/2013/09/256-01.pdf

Ortega, P. (2016). La ética de la compasión en la pedagogía de la alteridad. Revista Española de Pedagogía, 74(264), 243-264. https://reunir.unir.net/bitstream/handle/123456789/5055/ La-etica\%20de\%20la\%20compasion.pdf?sequence=1\&isAllowed=y

Ortega, P. y Gárate, A. (2017). Una escuela con rostro humano. Cetys Universidad.

Ortega, P. \& Romero, E. (2014). Subjetct's recuperation in education, Journal of Curriculum and Teaching, 3(1), 86-93. https://doi.org/10.5430/jct.v3n1p86

Ortega, P. y Romero, E. (2018). La pedagogía de la alteridad como paradigma de la educación para la paz. Teoría de la Educación. Revista Interuniversitaria, 30(1), 95-116. https:// doi.org/10.14201/teoredu30195116

Ortega, P. y Romero, E. (2019). A la intemperie. Conversaciones desde la pedagogía de la alteridad. Octaedro.

Ortega y Gasset, J. (1975). Historia como sistema. Revista de Occidente.

Pallarés, M. (2020). Educación bumanizada. Una aproximación a partir del legado de Heinrich Rombach. Estudios sobre Educación, 38, 9-27. https://doi.org/10.15581/004.38.9-27

Pallarés, M., Chiva, O., Planella, J. y López, R. (2019). Repensando la educación. Perfiles educativos, 41(163), 123-137 https://doi.org/10.22201/iisue.24486167e.2019.163.58843

Pinardi, S. (2015). La noción de "pasividad» en la ética de Enmanuel Levinas. Isegoría, (53), 647-650. https://doi.org/10.3989/isegoria.2015.053.10

Pérez-Guerrero, J. (2016). Ser humano como tarea. Ideas para una antropología de la educación de inspiración clásica. Revista Española de Pedagogía, 74(264), 227-241. https://reunir.unir.net/bitstream/handle/123456789/5054/Ser-humano-como-tarea. pdf?sequence $=1 \&$ isAllowed $=\mathrm{y}$

Ricoeur, P. (1996). Tiempo y narración. Vol. III. El tiempo narrado. Siglo XXI. 
Romano, C. (2015). El otro me llama a la responsabilidad. Apeiron. Estudios de filosofía, (3), 215-230. https://s3.amazonaws.com/wix-anyfile/voH3UOQSqLCRyplyxLgx_17\%20-\%20 El\%20otro\%20me\%20llama\%20a\%20la\%20responsabilidad.pdf

Rombach, H. (2007). El presente de la filosofía. Herder.

Schopenhauer, A. (1993). Los dos problemas fundamentales de la ética. Siglo XXI.

Van Manen, M. (2003). Investigación educativa y experiencia vivida. Idea Books.

Vila, E. (2008). La lectura como experiencia humana, pedagógica e intercultural. Revista Iberoamericana de Educación, 45(4), 1-7. https://rieoei.org/historico/ deloslectores/2281VilaCorregido.pdf

Zufiaure, B. y Hamilton, D. (2015). Cerrando círculos en educación. Morata. 